\title{
Job satisfaction determinants and assessment: the case of a Greek public agency under organisational change
}

\section{Efstratios Meimaridis}

School of Social Sciences,

Hellenic Open University,

Parodos Aristotelous 18, 26335, Patra, Greece

and

Single Agency for Social Insurance (EFKA),

Amerikis 12, 10671 Athens, Greece

Email: stratos.meimaridis@outlook.com

\section{Christina Diakaki*}

\author{
School of Social Sciences, \\ Hellenic Open University, \\ Parodos Aristotelous 18, 26335, Patra, Greece \\ and \\ School of Production Engineering and Management, \\ Technical University of Crete, \\ University Campus, 73100 Chania, Greece \\ Email: cdiakaki@isc.tuc.gr \\ *Corresponding author
}

\begin{abstract}
In 2017, the Single Agency for Social Insurance (EFKA) emerged in Greece via integrating the pre-existing independent insurance funds, with little, if any, involvement of the employees. As it is known that organisational changes may compromise job satisfaction and consequently organisational performance, it is beneficial for organisations to make efforts to ensure the satisfaction of employees and the first step in this respect is understanding and assessing their job satisfaction. Within this context, it is the aim of the study presented herein to identify the satisfaction determinants of EFKA employees, assess their satisfaction levels and highlight job aspects calling for attention and/or improvement. To this end, a questionnaire survey was undertaken and data were analysed with statistical techniques and action diagrams. The results of the analyses indicated several job dimensions with contributions to overall satisfaction, with the most important and at the same time critical the 'work tasks and development' dimension.
\end{abstract}

Keywords: job satisfaction determinants; job satisfaction assessment; organisational change; public sector; statistical analysis; action diagrams.

Reference to this paper should be made as follows: Meimaridis, E. and Diakaki, C. (2020) 'Job satisfaction determinants and assessment: the case of a Greek public agency under organisational change', Int. J. Decision Sciences, Risk and Management, Vol. 9, Nos. 1/2, pp.83-105. 
Biographical notes: Efstratios Meimaridis holds a degree in Economics (1991) from the National and Kapodistrian University of Athens and a Master in Business Administration (2018) from the Hellenic Open University. He has worked since 1989 as an accountant in the Greek private sector, since 1994 in the Greek public sector and specifically in the Social Insurance Funds TSA \& OAEE and since 2017 in EFKA. Since 2011, he served consecutively as the supervisor of the OAEE Payroll, Accounting and Budget Departments and currently of the EFKA Payroll Department.

Christina Diakaki holds a Diploma in Production and Management Engineering (1991), MSc in Operations Management (1993) and $\mathrm{PhD}$ in Operations Research (2000). Since 1999, she has been Adjunct Professor and Research Associate at several research and educational establishments in Greece and Cyprus (Technical University of Crete, Technological Educational Institutes of Crete and Kozani, Hellenic Open University, European University Cyprus). Since 1991, she has participated in numerous research projects sponsored by the European Commission, public authorities and private organisations. She serves as reviewer for several scientific journals and conferences, she is Associate Editor of the Engineering and Technology Institution's Intelligent Transport Systems journal and she is author and co-author of numerous research reports and papers in scientific and technical journals, and conference proceedings. Her research interests include decision analysis and operations research, and systems' analysis, modelling, simulation and optimisation with applications in the fields of transportation, energy and environment, and management.

\section{Introduction}

Reengineering is a management approach aimed at increasing the efficiency of an organisation. It typically adopts a bottom-up, system-wide approach to blend or streamline redundant programs, departments, jobs and processes (Neuman, 2003). Typically also, it requires the participation of employees in the whole process to ensure the acceptance, fit-for-purpose and smooth transition to any decided changes in contrast to the traditional approaches to reorganisation and restructuring, which adopt top-down approaches focusing in cost reduction with little, if any, participation of the employees. It is known, however, that any organisation reformation may face a significant employee resistance (Furst and Cable, 2008; Bateh et al., 2013) and carries, among others, the risk of compromising job satisfaction, which its turn carries the risk of compromising organisational competence and performance (Pick and Teo, 2017).

Several studies have found job satisfaction to be closely linked to organisational performance (see e.g., Mafini and Pooe, 2013; Ouedraogo and Leclerc, 2013; Bakotić, 2016). It is, thus, useful for any organisation undergoing changes to ensure that the benefits of aimed transitions are clearly communicated to employees, and that employees participate in the realisation of transitions and transitions are made as smooth as possible to minimise the risk of negative effects on job satisfaction.

Job satisfaction, called also employee satisfaction, is one of the most researched variables in the area of workplace psychology (Lu et al., 2012). Its assessment became popular in the 1930s, through anonymous employee surveys (Spector, 1997). Since then, it has been studied perhaps more frequently than any other concept in organisational 
sciences (Cranny et al., 1992) and associated with numerous organisational factors ranging from job design to leadership and beyond (Spector, 1997).

Job satisfaction may be defined as the way that people feel about their jobs and their different aspects (Spector, 1997), or as the emotional state of a person while appraising his/her job and/or job-related experiences (Locke, 1976). Literature provides evidently several different definitions about job satisfaction and clearly, there are a large number of factors that ultimately shape the satisfaction level of an employee, although it is not clear if there are specific measurement dimensions or if employee satisfaction just reflects an emotional state (Grigoroudis and Siskos, 2010). All these make its overall assessment a complex and difficult task and have given rise to the development of various measurement scales covering different facets of job satisfaction as well as overall satisfaction (Grigoroudis and Siskos, 2010). The complexity of the task has also led many researchers to focus on the study of the relationship of job satisfaction with specific job characteristics like workplace environment (e.g., Fassoulis and Alexopoulos, 2015), pay (e.g., Judge et al., 2010) and job security (e.g., Zheng et al., 2014) or a predefined subset of job characteristics (e.g., Harper et al., 2015), or focus on the relationship of job satisfaction with demographic characteristics such as age (e.g., Chaudhuri et al., 2015) and education level (e.g., González et al., 2016) or other business aspects such as organisational change (e.g., Gustafsson and Östberg, 2017; Pick and Teo, 2017), organisational performance (see e.g., Mafini and Pooe, 2013; Ouedraogo and Leclerc, 2013; Bakotić, 2016) and customer satisfaction (e.g., Raharjo et al., 2016).

In January 2017, the Single Agency for Social Insurance (EFKA) emerged in Greece via the integration of the eight main Greek social insurance funds with all of their different management/staffing arrangements. This significant merge has been a result of a political decision with reasons lying primarily to the sphere of economics (cost reduction, economic viability of the insurance system, etc.), which have become the number one driver behind several changes in the Greek public sector and beyond, due to the ongoing severe economic crisis. As a consequence, a traditional top-down reorganisation approach was adopted whereby little attention, if any, has been paid to the perspective of employees, although EFKA is currently one of the largest organisations in Greece with a workforce of over 8,000 persons. However, as mentioned earlier, any organisational change may compromise job satisfaction and consequently organisational performance. It is therefore beneficial for any organisation, to make any effort to ensure the satisfaction and well-being of its employees; and the first step to achieve such a goal, is to understand the determinants of their job satisfaction and assess their current satisfaction levels. Within this context, it is the main aim of the study presented in this paper to take forward this first step with regard to the EFKA employees, explore and identify their job satisfaction determinants and assess their current satisfaction levels. It is also an aim of the study to highlight dimensions that need special attention in order to preserve or, where necessary, improve employee satisfaction, thus preserving or even improving the organisation's own competence and performance.

To achieve the aforementioned goals, a structured-questionnaire survey has been undertaken and the collected information has been analysed with the use of statistical techniques, regression analysis in particular, and action diagrams. As the purpose of the study has been exploratory, unlike other studies, which focus on a limited subset of job characteristics, an effort has been made to consider, to the extent possible, many and diverse aspects of job satisfaction. 
Although the study presented herein focuses on a specific organisation, the approach followed and the analysis findings may be useful to any organisation undergoing or planning to undergo a change, and/or wishing to identify the determinants of its employees' satisfaction and assess, against them, the satisfaction of its employees and/or to identify job aspects that should be improved. Especially for Greece, the study is particularly important as there is little research activity in the assessment of job satisfaction especially with respect to the public sector and organisations that undergo major reforms. It is also important to notice that even relevant and relatively recent studies, as for example the work of Demoussis and Giannakopoulos (2007), who studied the differences in job satisfaction of employees in the public and private sector, need to be revisited, as the economic crisis that started in Greece around 2009 has affected not only the economic status of the employees, but also their attitudes to job such as satisfaction, productivity and commitment (Markovits et al., 2014).

The rest of the paper is organised in four more sections. Section 2 presents the organisation under study, while Section 3 describes the study's methodology and tools. Section 4 presents and discusses the results and findings of the study and Section 5 , finally summarises conclusions, outlines limitations and proposes directions for future work.

\section{The Single Agency for Social Insurance (EFKA) of Greece}

Social insurance ensures the transfer of resources from active to inactive social groups in order to maintain a decent standard of living. Additionally, it covers the loss of income in the event of temporary or permanent inability (illness, disability, unemployment or accident). In Greece, social insurance evolved gradually starting in 1836, based upon the basic principle that the current generation of active labour should fund the retirement provision of previous generations (Meimaridis, 2018). Over the years, this system developed several general pathologies that were witnessed as a threat to its viability. The causes were specific country features related to the structure of the insurance system and the state, demographic pathologies, the polydispersion of the Social Insurance Funds, reduced funding, social insurance contributions evasion practices, lack of managerial autonomy of reserves and mismanagement.

Over the past three decades, the Greek social insurance system has undergone various changes and legislative interventions, mainly aiming towards its financial rehabilitation (Meimaridis, 2018). The latest and most important intervention emerged through the establishment of Law 4387/2016 on the Single Social Insurance System (reform of the insurance/pension system, gaming and income tax arrangements and other provisions), which was a radical step to the reform of the operations of social insurance in Greece towards a unified insurance system. Under this law, a new agency emerged via the integration of the eight main previous social insurance funds, which acquired all their different features and systems such as different sets of criteria for contributions payable and entitlements that are due, different management and staffing arrangements and different organisational cultures and procedures. The aim was to bring under one roof social insurance contributions, pensions and benefits. Since Law 4387/2016 passed in May 2016, numerous Ministerial decrees were issued in order to provide additional changes necessary for the implementation of EFKA. 
As a result of the aforementioned law and subsequent decrees, EFKA came in existence in January 1, 2017, with operations that are still carried out with delays, shortcomings, weaknesses and errors, which are not surprising given the size of the merging project and the minimal preparation time that was provided. At the same time, EFKA remains a state institution and therefore must comply with a frame of rules and obligations just like the wider public sector in Greece. This means that even though it has some partial autonomy, EFKA is heavily dependent on the State budget and regulations to carry out its business. The new agency currently operates under a temporal organisation chart, while the final one still remains to be defined. Its Head Office is in Athens, and is supported by a network of approximately 350 local offices throughout Greece, which mainly provide services to the active and retired members (e.g., collect national security contributions, provide pensions and benefits).

EFKA occupies some 8,000 employees. Following the general trend of the public sector in Greece and abroad, it is mainly occupied by women (OECD, 2017), approximately $64 \%$ of EFKA employees are women (Meimaridis, 2018). Moreover, just like the rest of the public sector in Greece, EFKA faces a rapidly ageing population, caused by the mass resignations of the period 2010-2015. The median of EFKA employees' age distribution is 48 years, while the first and third quartiles of age distribution are 42 and 54 years, respectively (Meimaridis, 2018). This means that half of the employees are over 48 years old, while half of EFKA employees are between 42 and 54 years old. Finally, approximately $43 \%$ of EFKA employees hold a higher education degree (Diploma or above), while about $16 \%$ are assigned in management-related positions (Meimaridis, 2018).

\section{Methodology and tools}

As mentioned in Section 1, the main aim of the study presented herein was to identify the job satisfaction determinants of EFKA employees and to assess the current satisfaction levels of employees against them. To this end, a structured-questionnaire has been developed covering ten major satisfaction dimensions, which have been revealed as important facets of job satisfaction according to an extensive literature survey (Meimaridis, 2018) of both proposed measurement scales such as the Minnesota satisfaction questionnaire (MSQ), the brief index of affective job satisfaction (BIAJS), the job descriptive index (JDI), etc., and past empirical studies on the subject. The considered dimensions include the following (Meimaridis, 2018):

1 location and functionality of workplace

2 cleanliness and hygiene of workplace

3 workplace infrastructure

4 direct collaborators or subordinates

5 supervisors

6 work tasks and development

7 education and training 
8 earnings

9 working hours and leaves

10 additional services and benefits.

The aforementioned satisfaction dimensions were then decomposed into sub-dimensions, logically related to each other, which comprised the basis for the development of the main questions included in the distributed questionnaire (Meimaridis, 2018). Figure 1 displays graphically the structure and operational flow of the considered job satisfaction dimensions.

Figure 1 Structure and operational flow of considered job satisfaction dimensions and sub-dimensions

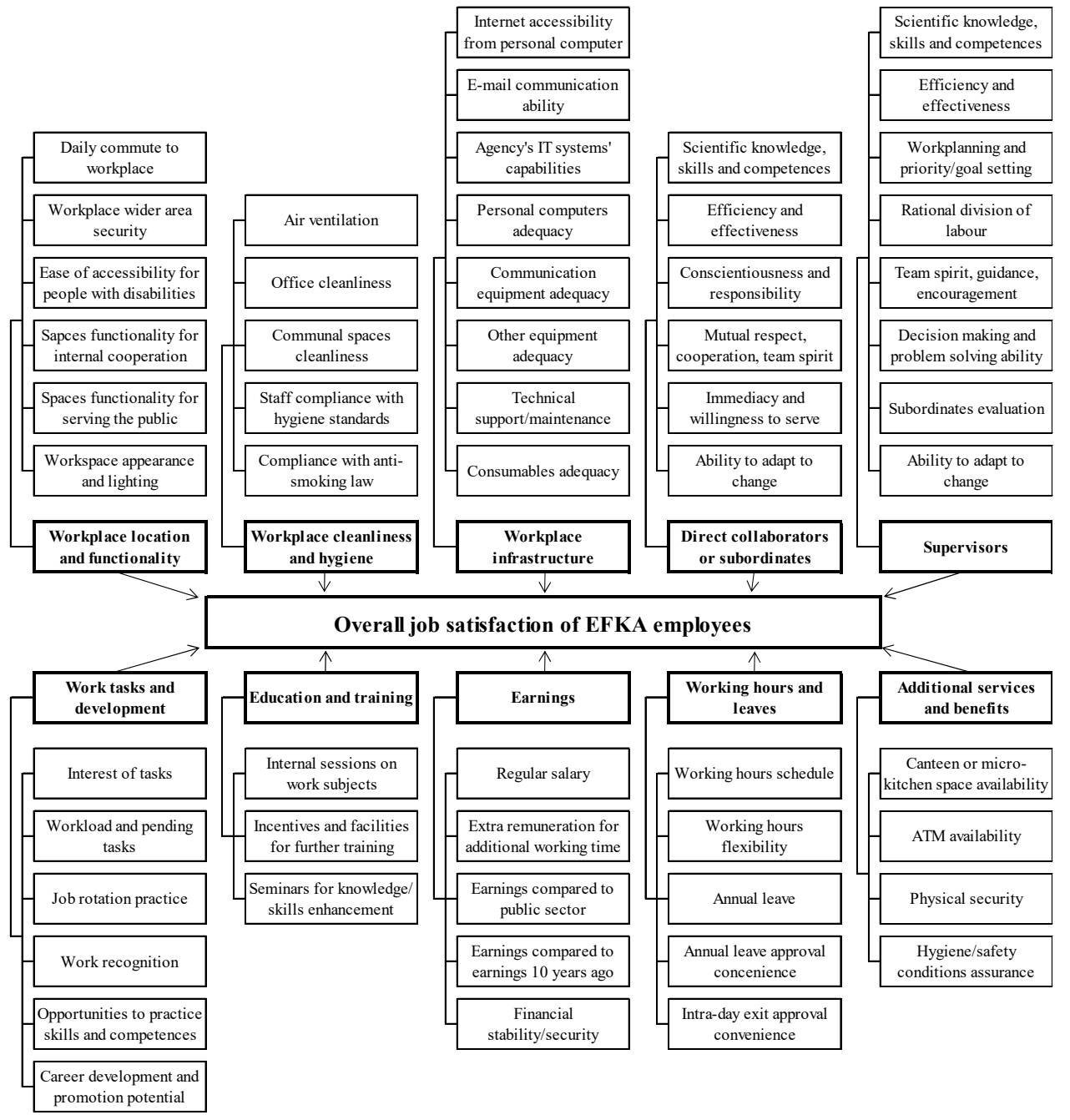

Scientific knowledge, skills and competences

Efficiency and effectiveness

Workplanning and priority/goal setting

Decision making and problem solving ability

Subordinates evaluation

bility to adapt to change

All questions were close-ended so respondents had to choose from a fixed set of answers. According to the questions, respondents had to rate their satisfaction level with respect to 
each defined job satisfaction dimension and sub-dimension plus their overall job satisfaction, based on a 5-level Likert-type scale (1-very dissatisfied, 2-dissatisfied, 3-neither dissatisfied nor satisfied, 4-satisfied, 5-very satisfied), typically used in such surveys (Grigoroudis and Siskos, 2010). In addition to the above questions, a set of additional questions were used to collect demographic-type data like age, education level, etc. of the respondents.

To ensure reliability and validity of the developed questionnaire, a pilot survey took place before the actual survey, while Cronbach's alpha was used to assess the internal consistency of the questionnaire after data collection (Meimaridis, 2018). Cronbach's alpha was estimated both for the ten considered dimensions as a group and for the ten groups of sub-dimensions considered for each dimension. Its value was found 0.803 for the group of the ten satisfaction dimensions suggesting acceptable internal consistency (Field, 2009). The same conclusion was also drawn for the ten groups of sub-dimensions as the corresponding Cronbach's alpha values were found to lie in the range $0.751-0.967$.

The questionnaire, which resulted after a few modifications following the aforementioned reliability and validity checks, was distributed to 300 employees located in ten different EFKA premises that house services of EFKA in Athens, including EFKA's headquarters (Meimaridis, 2018). A quota-like sampling technique was adopted to avoid exaggeration in demographic characteristics and ensure that employees from all previous funds were included in the collected sample.

The collected data were then checked for correctness and completeness and entered in the well-known IBM SPSS Statistics software for the statistical analysis, which took place mainly in two axes (Meimaridis, 2018):

- Descriptive statistics have been used to reveal the sample profile and its average stand against the considered dimensions and sub-dimensions of job satisfaction.

- Multiple linear regression analysis has been adopted to reveal the importance given by employees to the examined job characteristics and therefore help in the identification of the critical satisfaction dimensions.

In the context of a satisfaction survey, the dependent variable of the regression analysis represents the overall satisfaction judgment and the independent variables the satisfaction according to the considered satisfaction dimensions. Consequently, the estimated coefficients, which indicate the contribution of the independent variables to the dependent, may reveal the importance given by the respondents to each one of the considered satisfaction dimensions and therefore identify the critical ones (Grigoroudis and Siskos, 2010).

Within the present study, several multiple linear regressions were performed in order to identify the critical sub-dimensions within each considered main job satisfaction dimension, as well as the dimensions that are critical for the overall job satisfaction (see Figure 1). The results of the linear regressions were then combined with the average satisfaction values obtained for each dimension, sub-dimension and overall job satisfaction to produce action diagrams.

Action diagrams, also known as decision, strategic, perceptual or performanceimportance maps, are very useful in that they indicate the strong and the weak points of satisfaction and via a gap type analysis among what is desired (importance) and what is perceived (performance) assist in defining and prioritising the required 
improvement efforts (Grigoroudis and Siskos, 2010). Action diagrams resemble the strengths-weaknesses-opportunities-threats (SWOT) analysis. Each map is divided into quadrants as Figure 2 displays, according to performance (high/low) and importance (high/low), which are used to classify actions (Grigoroudis and Siskos, 2010). In the examined case:

- Performance corresponds to the average satisfaction expressed by the surveyed sample to the different dimensions and sub-dimensions of job satisfaction.

- Importance is revealed by the standardised values of the coefficients estimated through the regression analyses.

For the needs of the present study, 11 action diagrams have been developed, falling in one of the following types:

- One overall job satisfaction action diagram comprising the ten main job satisfaction dimensions, which were found to be critical; this diagram has been used to classify and prioritise the dimensions according to their performance and importance with respect to overall job satisfaction.

- Ten dimension-specific action diagrams, each comprising the critical sub-dimensions of one main job satisfaction dimension; these diagrams have been used to classify and prioritise sub-dimensions according to their performance and importance with respect to the corresponding job satisfaction dimension.

Figure 2 Action diagram general structure

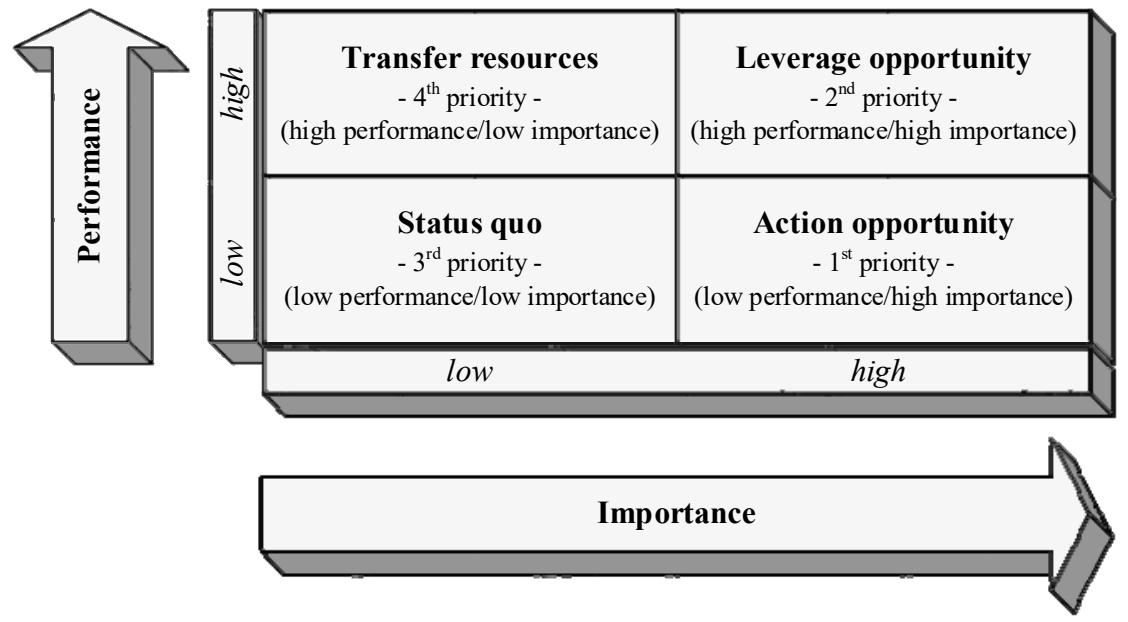

The aforementioned action diagrams are important for they may help the organisation to identify and prioritise job-related improvement efforts, since according to their typical interpretation, as adopted in the context of a job satisfaction study:

- $\quad$ The bottom-right that is the action opportunity (low performance/high importance) quadrant comprises dimensions or sub-dimensions, depending on the diagram type, that need attention and should be the improvement priority number one for the organisation, as they have low satisfaction levels, although their importance, as 
derived by the regression analysis, has been rather high. The improvement of the satisfaction levels of this quadrant's dimensions/sub-dimensions is generally expected to lead to the improvement of the satisfaction levels of the corresponding dimension or overall job satisfaction, depending on the type of the diagram.

- The second priority for the organisation should be given to the satisfaction dimensions or sub-dimensions, in the top-right quadrant that is the leverage opportunity (high performance/high importance) quadrant. This quadrant comprises satisfaction dimensions or sub-dimensions that have high satisfaction levels, which should be preserved as their derived importance is also high.

- The third priority dimensions or sub-dimensions are indicated in the bottom-left that is the status quo (low performance and low importance) quadrant. This quadrant comprises job satisfaction dimensions or sub-dimensions, which are not considered as important by the employees, thus require no current action by the organisation. Nevertheless, the organisation should be aware of these dimensions/sub-dimensions as they may become important in the future and urge for improvement actions due to their low satisfaction levels.

- Last priority for the organisation should comprise the dimensions or sub-dimensions, in the top-left that is the transfer resources (high performance/low importance) quadrant, as they demonstrate relatively high satisfaction levels, despite their derived low importance for the employees.

The action diagrams may be constructed based on the absolute or relative values of performance and importance (Grigoroudis and Siskos, 2010); the former are called raw action diagrams and the latter relative. The relative action diagrams use the relative values of performance and importance thus overcoming the problem to assess the cut-off level for the importance and the performance axis (Grigoroudis and Siskos, 2010).

In this study, relative action diagrams have been developed with the relative performance and importance calculated according to the following formulas:

$$
\begin{gathered}
X_{i}^{\prime}=\frac{X_{i}-\bar{X}}{\sqrt{\sum_{i=1}^{n}\left(X_{i}-\bar{X}\right)^{2}}} \\
b_{i}^{\prime}=\frac{b_{\mathrm{ST}, i}-\bar{b}_{\mathrm{ST}}}{\sqrt{\sum_{i=1}^{n}\left(b_{\mathrm{ST}, i}-\bar{b}_{\mathrm{ST}}\right)^{2}}}
\end{gathered}
$$

where $X_{i}$, with $i=1,2, \ldots, n$, is the satisfaction according to dimension $i, n$ is the number of the considered satisfaction dimensions, $X_{i}^{\prime}$ and $b_{i}^{\prime}$ are the relative performance and importance respectively of satisfaction dimension $i, b_{\mathrm{ST}, i}$ is the standardised value of the regression coefficient $b_{i}$ or, in the context of this study, the standardised importance of satisfaction dimension $i$, and $\bar{X}$ and $\bar{b}_{\mathrm{ST}, i}$ are the mean values of $X_{i}$ and $b_{\mathrm{ST}, i}$, respectively. It should be noted here that the standardised $b_{\mathrm{ST}, i}$ rather than the 
unstandardised $b_{i}$ coefficients have been used, as the former use standard deviations as their units, which means that the considered variables can be easily compared to each other.

\section{Results and discussion}

The questionnaire developed as described in Section 3 was distributed to 300 EFKA employees between January 19 and 31, 2018 and completed questionnaires were collected in the first days of February. Overall, 238 questionnaires were collected, ten of which were discarded as they were not properly filled. The response rate was thus around $77 \%(227 / 300)$ and the sampling ratio, that is the ratio of sample size to the size of the target population, around $3 \%$.

The profile of the survey respondents may be summarised in the following points (Meimaridis, 2018):

- The ratio of women and men in the sample (see Table 1) successfully approximated the ratio in the actual population (see Section 2), which is dominated by women.

- The age distribution of respondents (see Table 2) approximated the age distribution of the population (see Section 3), reflecting well its ageing trend.

- Approximately half of the respondents hold a higher education degree (see Table 3), which is close to the actual population (see Section 3).

- The ratio of work positions in the sample (see Table 4) successfully approximated the ratio in the actual population (see Section 2).

- The respondents reported an annual income in the range 10,000-20,000 $€$ with more than half of them reporting income in the range 10,000-15,000€ (see Table 5). This result confirms the uniformity of the current payroll system of the public sector under which most employees end up with similar remunerations, despite their diverse characteristics concerning work maturity, educational level, etc.

The above points indicate that the surveyed sample has characteristics that reflect quite well the characteristics of the total population of EFKA employees.

As far as satisfaction is concerned, Figure 3 summarises and graphically displays the satisfaction levels with respect to the overall job satisfaction, as well as with respect to the individual job satisfaction dimensions, as expressed by the respondents of the survey. The figure reveals the following (Meimaridis, 2018):

Table 1 Gender statistics of sample

\begin{tabular}{lcc}
\hline Gender & Frequency & Percentage \\
\hline Female & 152 & 67.0 \\
Male & 75 & 33.0 \\
Total & 227 & 100.0 \\
\hline
\end{tabular}


Table 2 Age statistics of sample

\begin{tabular}{lcc}
\hline Age range & Frequency & Percentage \\
\hline Up to 30 years old & 0 & 0.0 \\
31 to 40 years old & 50 & 22.0 \\
41 to 50 years old & 117 & 51.5 \\
51 to 60 years old & 55 & 24.2 \\
Over 60 years old & 5 & 2.2 \\
Total & 227 & 100.0 \\
\hline
\end{tabular}

Table 3 Education level statistics of sample

\begin{tabular}{lcc}
\hline Education level & Frequency & Percentage \\
\hline Primary education & 1 & 0.4 \\
Secondary education & 112 & 49.4 \\
Higher education & 114 & 50.2 \\
Total & 227 & 100.0 \\
\hline
\end{tabular}

Table 4 Work positions statistics of sample

\begin{tabular}{lcc}
\hline Age range & Frequency & Percentage \\
\hline Employee & 194 & 85.5 \\
Team supervisor & 29 & 12.8 \\
Chief of division & 4 & 1.8 \\
Total & 227 & 100.0 \\
\hline
\end{tabular}

Table 5 Annual income statistics of sample

\begin{tabular}{lcc}
\hline Annual income range & Frequency & Percentage \\
\hline Up to $10,000 €$ & 14 & 6.2 \\
$10,001-15,000 €$ & 128 & 56.4 \\
$15,001-20,000 €$ & 65 & 28.6 \\
$20,001-25,000 €$ & 11 & 4.8 \\
$25,001-30,000 €$ & 7 & 3.1 \\
Over $30,000 €$ & 2 & 0.9 \\
Total & 227 & 100.0 \\
\hline
\end{tabular}

Table 6 Overall job satisfaction statistics of sample

\begin{tabular}{lcc}
\hline Overall job satisfaction & Frequency & Percentage \\
\hline Very dissatisfied & 2 & 0.9 \\
Dissatisfied & 56 & 24.7 \\
Neither satisfied nor dissatisfied & 116 & 51.1 \\
Satisfied & 52 & 22.9 \\
Very satisfied & 1 & 0.4 \\
Total & 227 & 100.0 \\
\hline
\end{tabular}


- About half of the respondents (51.1\%) were, overall, neither satisfied nor dissatisfied from their work at EFKA. The remaining respondents expressed, at almost equal levels, satisfaction and dissatisfaction $(22.9 \%$ and $24.7 \%$, respectively) with the latter being marginally in the lead. A rather negligible percentage of respondents expressed high satisfaction or dissatisfaction levels (1.3\% in total).

- The respondents were satisfied or very satisfied with respect to the dimensions of 'working hours and leaves' (69.2\%), 'direct collaborators or subordinates' $(68.7 \%)$ and 'supervisors' (65.7\%).

- The respondents were dissatisfied or very dissatisfied with respect to the dimensions of 'additional services and benefits' (73.1\%), 'education and training' (59\%), 'earnings' (56.8\%), 'cleanliness and hygiene of workplace' (45.8\%) and 'workplace infrastructure' (43.7\%).

- The respondents were neutral (neither satisfied nor dissatisfied) with respect to the dimensions of 'work tasks and development' (46.3\%) and 'location and functionality of workplace' (44.5\%).

Figure 3 Satisfaction levels (in \%) expressed by the EFKA employees with respect to overall job satisfaction and satisfaction at the main dimensions

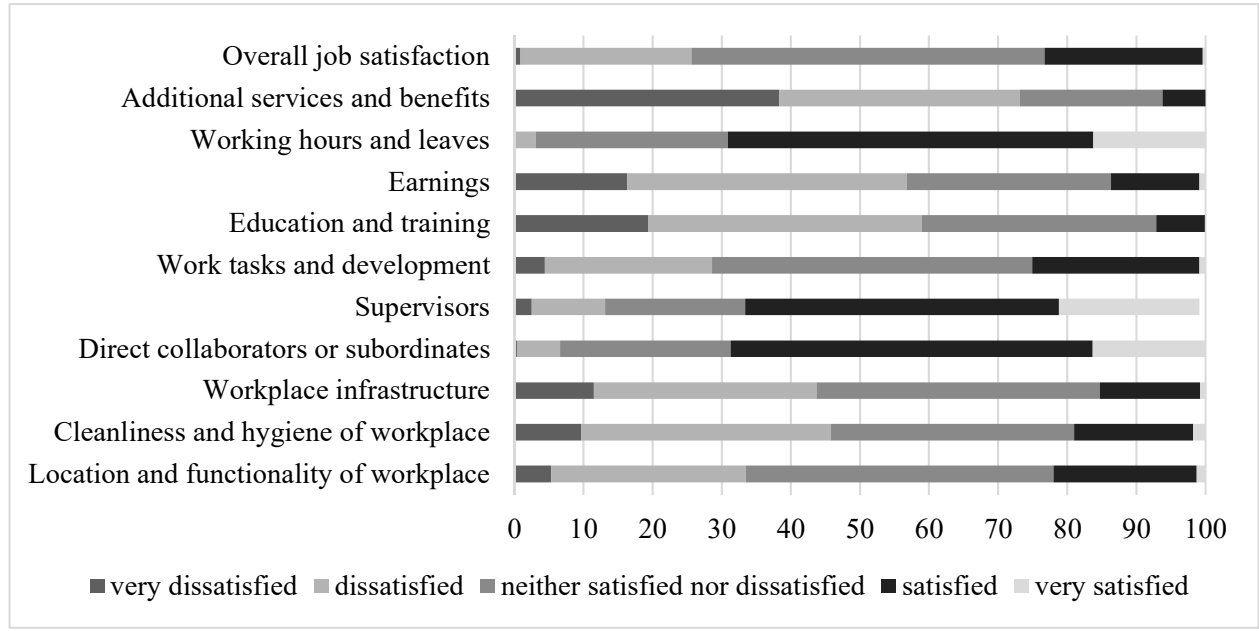

Figure 3 corresponds to the satisfaction of respondents with respect to the different dimensions and overall. They actually comprise the satisfaction performance metrics of the study, which may lead to really useful conclusions and guide any potential improvement actions on behalf of the organisation, if they are combined with the importance given to the different satisfaction dimensions by the employees. To derive importance, regression analyses were used as described in Section 3.

In total, eleven multiple regression analyses were performed (Meimaridis, 2018):

- Ten dimension-specific regression analyses. In each of these analyses, $Y$ represents the job satisfaction at a specific dimension and $X_{i}$ the satisfaction at the respective sub-dimensions (see Figure 1), as expressed by the respondents to the survey. 
- A regression analysis with $Y$ the overall job satisfaction and $X_{i}$ the satisfaction at job satisfaction dimension $i$ (see Figure 1), as expressed by the respondents to the survey.

All developed dimension-specific regression models had good fit to the corresponding data, as their adjusted coefficients of determination $R^{2}$ were found with values in the range $0.724-0.911$ (see Table 7). This means that the variations observed in the values of the corresponding satisfaction dimensions can be explained by the respective data at percentages in the range 72.4-91.1\%, which is considered high. Nevertheless, not all subdimensions were found to have a statistically significant contribution to their corresponding satisfaction dimensions. Specifically (Meimaridis, 2018):

- With respect to dimension 'cleanliness and hygiene of the workplace',

sub-dimension 'the cleanliness of communal spaces' has not been found to make any statistically significant contribution $(p$-value $=0.097>0.05)$. This may be explained by the fact that this sub-dimension has not a direct impact on the employees' well-being; it is actually the only sub-dimension of this specific job satisfaction dimension that has no direct impact.

- With respect to dimension 'workplace infrastructure', sub-dimension 'internet accessibility from your personal computer' has not been found to make any statistically significant contribution $(p$-value $=0.844>0.05)$. With so many jobs lost in the last decade, it is likely that employees have less time to waste as they spend additional time on their increased job responsibilities. Thus, internet access could potentially be considered as an indifferent bonus.

- With respect to the dimension 'collaborators or subordinates', sub-dimension 'collaborators' immediacy and willingness to serve' has not been found to make any statistically significant contribution $(p$-value $=0.471>0.05)$. This may be explained by the fact that this particular sub-dimension has an indirect effect on the collaborators, as it is mostly perceived through the third parties, i.e., the public.

- With respect to the dimension 'supervisors', sub-dimensions 'supervisors' scientific knowledge, skills and competences', 'planning work and setting priorities and realistic goals' and 'the encouragement of team spirit and provision of guidance where needed' have not been found to make any statistically significant contributions ( $p$-values $=0.892 ; 0.333 ; 0.206>0.05)$. This finding is in line with the trend observed also in the aforementioned dimensions, where sub-dimensions not directly affecting the employees, have been found to be statistically insignificant. It is expected that a supervisor, characterised by rational division of work and rational evaluation of his/her subordinates, is more attractive and increases more the employees' job satisfaction than a supervisor whose charisma is planning, scientific knowledge and provision of guidance. And although the insignificance of guidance as a determinant of job satisfaction may be considered uncanny, it should not be forgotten that one of the strengths of EFKA is the experienced staff, who possibly have no reason to value guidance above other aspects. 
Table 7 Fit indices for dimension-specific and overall job satisfaction models

\begin{tabular}{lcc}
\hline Dependent variable & Adjusted $R^{2}$ & p-value \\
\hline Satisfaction from location and functionality of workplace & 0.731 & 0.000 \\
Satisfaction from cleanliness and hygiene of workplace & 0.724 & 0.000 \\
Satisfaction from workplace infrastructure & 0.738 & 0.000 \\
Satisfaction from direct collaborators or subordinates & 0.841 & 0.000 \\
Satisfaction from supervisors & 0.911 & 0.000 \\
Satisfaction from work tasks and development & 0.815 & 0.000 \\
Satisfaction from education and training & 0.856 & 0.000 \\
Satisfaction from earnings & 0.776 & 0.000 \\
Satisfaction from working hours and leaves & 0.747 & 0.000 \\
Satisfaction from additional services and benefits & 0.825 & 0.000 \\
Overall job satisfaction & 0.540 & 0.000 \\
\hline
\end{tabular}

Despite the generally good fit of the dimension-specific regression models, not all job satisfaction dimensions were found to make a statistically significant contribution to the overall job satisfaction (see Table 8). Specifically, the satisfaction dimensions 'collaborators or subordinates', 'education and training' and 'additional services and benefits' have not been found to make any statistically significant contribution (see $p$-values $>0.05$ in Table 8). Moreover, the overall job satisfaction model fit to data is not very high as indicated by the value of the adjusted coefficient of determination $R^{2}$, which is in this case 0.540 , meaning that the developed model explains some $54 \%$ of the variation observed in overall satisfaction. Still the model is acceptable as it is known that $R^{2}$-values lower than 0.50 are common in models trying to explain human behaviour (Frost, 2017).

Table 8 Statistical significance of independent variables in overall job satisfaction model

\begin{tabular}{lc}
\hline Independent variable & p-value \\
\hline Satisfaction from location and functionality of workplace & 0.033 \\
Satisfaction from cleanliness and hygiene of workplace & 0.025 \\
Satisfaction from workplace infrastructure & 0.014 \\
Satisfaction from direct collaborators or subordinates & 0.967 \\
Satisfaction from supervisors & 0.046 \\
Satisfaction from work tasks and development & 0.000 \\
Satisfaction from education and training & 0.266 \\
Satisfaction from earnings & 0.012 \\
Satisfaction from working hours and leaves & 0.028 \\
Satisfaction from additional services and benefits & 0.222 \\
\hline
\end{tabular}

As far as the satisfaction dimension 'collaborators or subordinates' is concerned, the identified insignificant contribution to overall job satisfaction could be a side effect caused by the recent merge of the Insurance Funds in EFKA. Each previous fund had its own philosophy, values and beliefs. The recent mix-up of employees from different backgrounds decreases potentially - at least for the present time - the significance of the 
satisfaction that is caused by the relationships with the collaborators. With respect to the dimension 'education and training', the identified insignificant contribution may look surprising from a first sight, as it contrasts with findings of other studies (see e.g., Schmidt, 2007; Chaudhary and Bhaskar, 2016). Nevertheless, it may be explained, at least partially, by the combined effect of factors such as the age of the sample (and the overall population), which is rather far (see Table 3) from the ages in which professional development is typically sought through education and training activities, the increased, as mentioned earlier, job responsibilities that do not leave sufficient time for the required study typically accompanying the education-related activities and the attitude of many employees in the public sector who consider training as just another annoying disturbance of their daily routine. This specific finding may also be explained by the findings of an older study by Mottaz (1984), which indicates that education has two effects on overall job satisfaction; an indirect positive and a direct negative. More specifically, education may increase job satisfaction when it is rewarded according to the traditional educational payoffs of intrinsic nature such as task autonomy, significance and involvement. When, however, education does not lead to greater intrinsic rewards and then job satisfaction may be significantly reduced. This occurs because higher education qualifications are associated with higher aspirations or work values (Mottaz, 1984). Thus, for employees who receive equal levels of intrinsic rewards, job satisfaction tends to be considerably lower especially among the higher educated employees, that in the case of EFKA comprise a high staff ratio $(50.2 \%$ in the sample, see Table $3 ; 43 \%$ in the total populations, see Section 2). Another aspect of this problem is that in the private sector, employees may indeed have the opportunity to exploit their qualifications. In a public organisation, however, autonomy, involvement and other rewards that should accompany more qualified personnel are not provided to the extent they should be. Finally, with respect to the dimension 'additional services and benefits', the identified insignificant contribution is not surprising, as it follows the same trend observed above in the sample responds according to which satisfaction dimensions with no direct impact to employees are most likely perceived by them as insignificant.

To further analyse the collected data so as to reveal the dimensions and subdimensions that are critical for the satisfaction of EFKA employees and/or call for improvement efforts, relative action diagrams were developed (see Figures 4 and 5), as described in Section 4. The diagram comprises only dimensions and sub-dimensions that according to the preceding regression analyses were found to make a statistically significant contribution in their respective context.

An analysis of the dimension-specific relative action diagrams of Figure 4 reveals at first that no major gaps exist among the performance and importance of the considered job satisfaction sub-dimensions. Moreover, in all but the dimension of 'satisfaction from earnings', there are sub-dimensions that comprise strong points for that carry high levels of both importance and performance to the employees (see leverage opportunity, i.e., top-right quadrants in Figure 4). These sub-dimensions should be treated with care by the new integrated agency in order to preserve their, currently observed, high satisfaction levels. Due to their increased importance to the employees, any shift in performance could easily drop them to the action opportunity quadrants (bottom-right) along with the other sub-dimensions, which, being already therein, call for attention and improvement. And there are quite enough sub-dimensions already calling for attention and improvement in all but the dimensions of 'satisfaction from cleanliness and hygiene of 
workplace' and 'satisfaction from working hours and leaves' (see action opportunity, i.e., bottom-right quadrants in Figure 4). Moreover, it should not be forgotten that the subdimensions falling currently in the status quo quadrants (see bottom-left quadrants in Figure 4) comprise sub-dimensions that, due to their currently observed low performance, may easily move to the action opportunity (bottom-right) quadrants, thus becoming also number one priorities, should they become more important to the employees in the future.

Figure 4 Dimension-specific relative action diagrams, (a) location and functionality of workplace (b) cleanliness and hygiene of workplace (c) workplace infrastructure (d) supervisors (e) work tasks and development (f) earnings (g) working hours and leaves (see online version for colours)

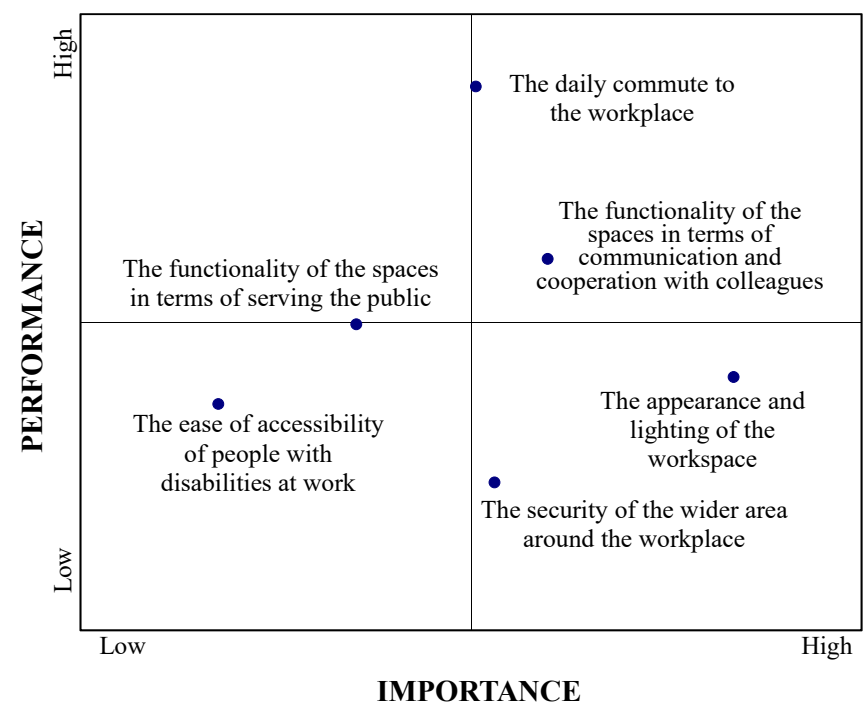

(a)

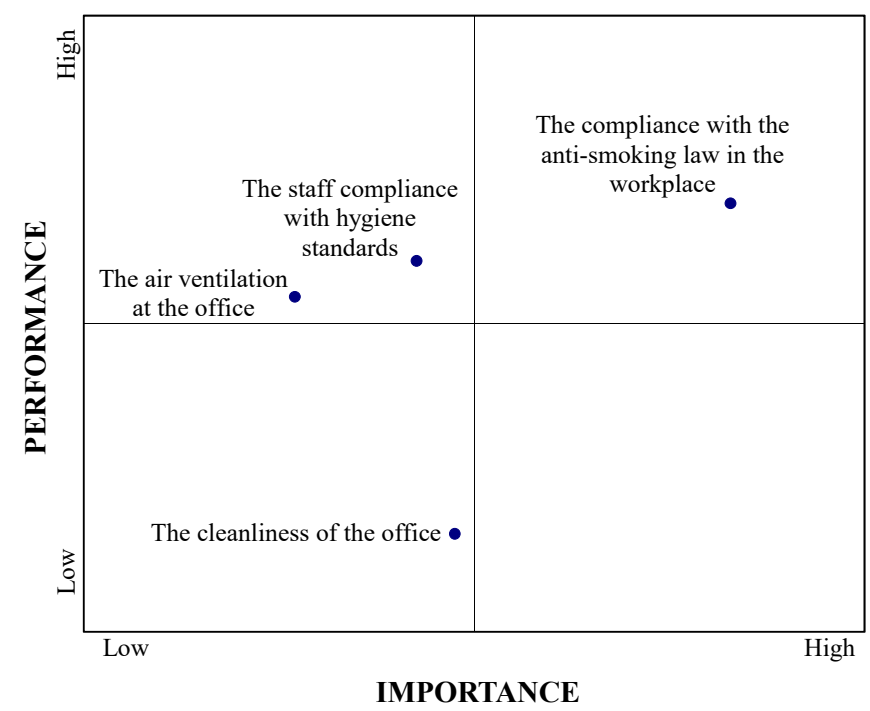

(b) 
Figure 4 Dimension-specific relative action diagrams, (a) location and functionality of workplace (b) cleanliness and hygiene of workplace (c) workplace infrastructure (d) supervisors (e) work tasks and development (f) earnings (g) working hours and leaves (continued) (see online version for colours)

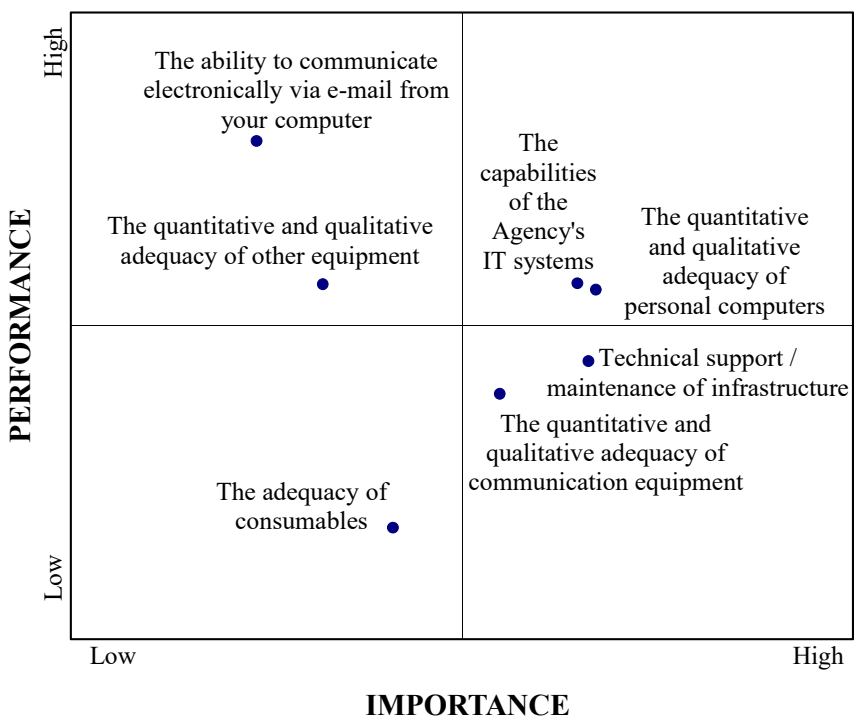

(c)

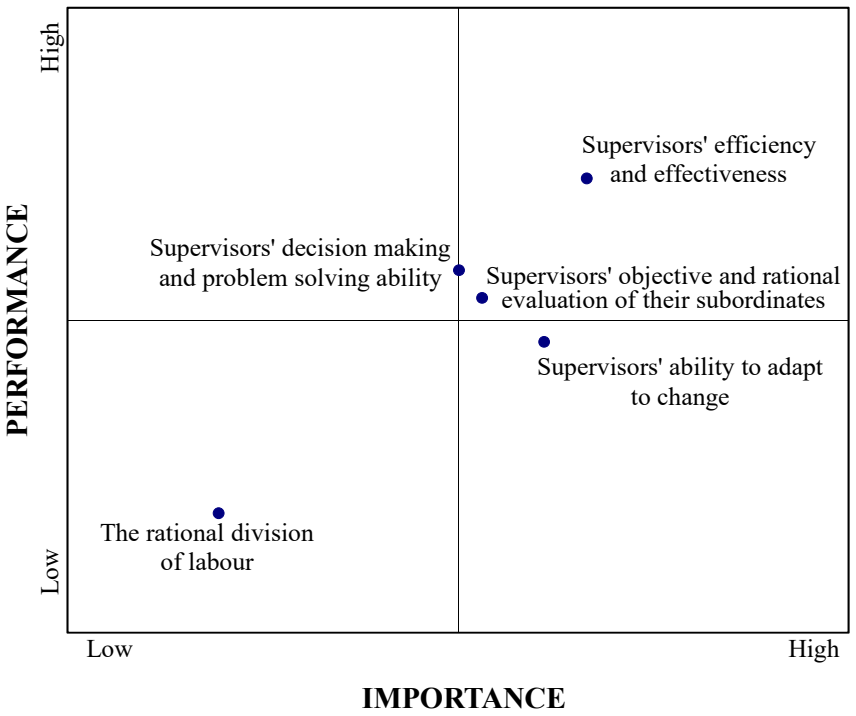

(d) 
Figure 4 Dimension-specific relative action diagrams, (a) location and functionality of workplace (b) cleanliness and hygiene of workplace (c) workplace infrastructure (d) supervisors (e) work tasks and development (f) earnings (g) working hours and leaves (continued) (see online version for colours)

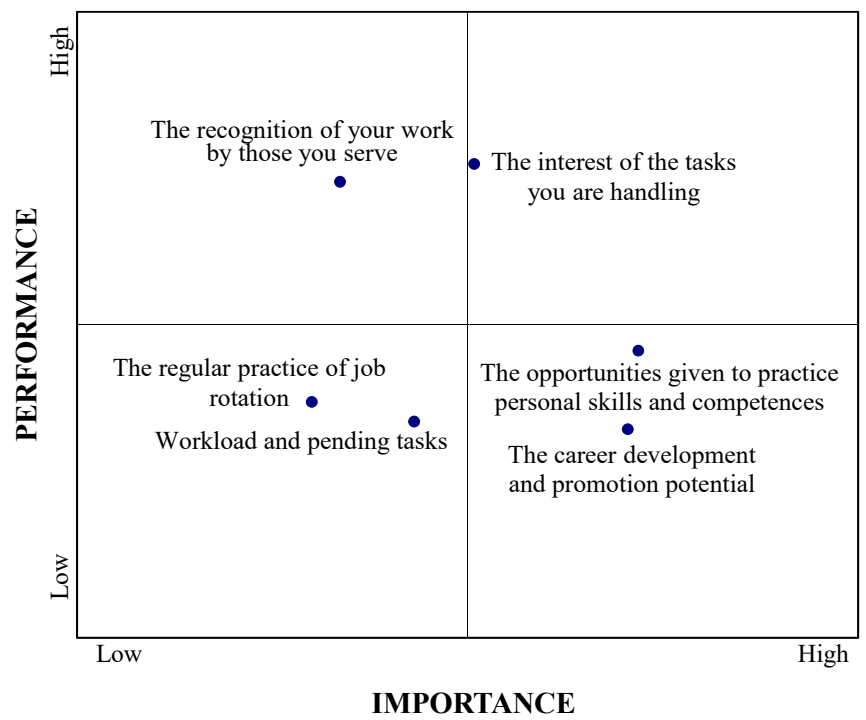

(e)

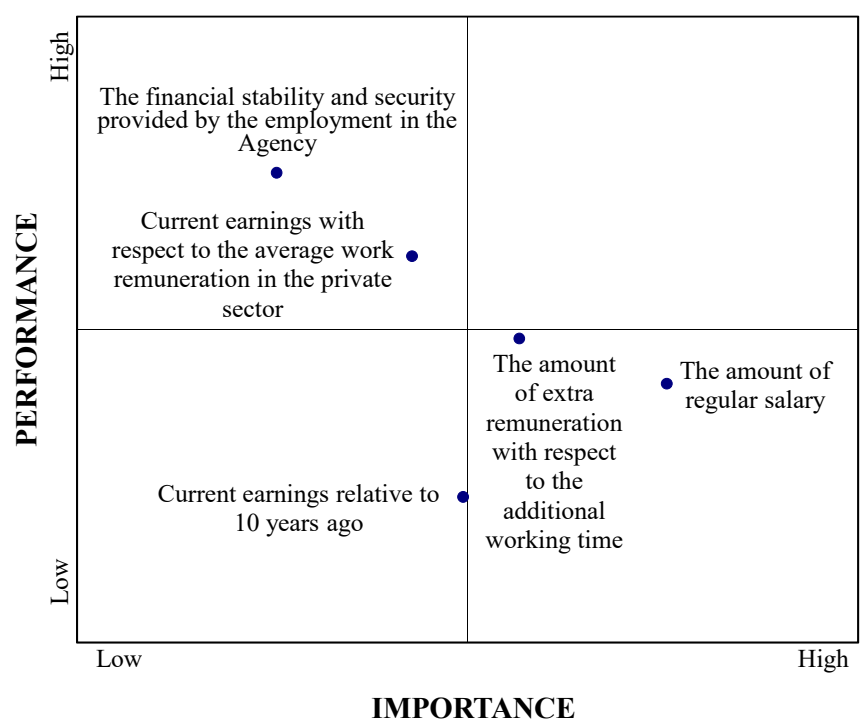

(f) 
Figure 4 Dimension-specific relative action diagrams, (a) location and functionality of workplace (b) cleanliness and hygiene of workplace (c) workplace infrastructure (d) supervisors (e) work tasks and development (f) earnings ( $g$ ) working hours and leaves (continued) (see online version for colours)

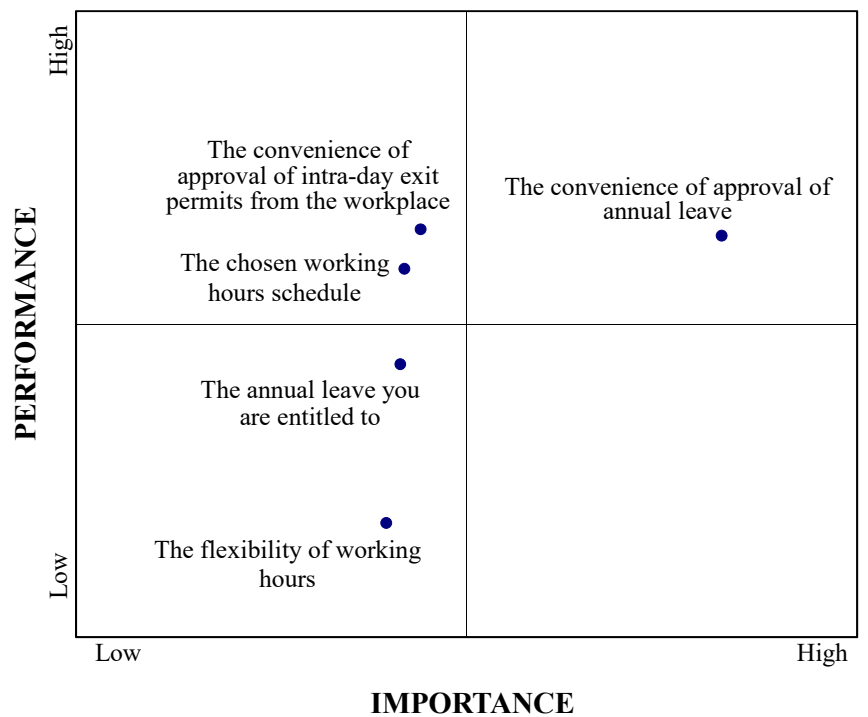

(g)

Despite the fact that according to the relative action diagrams of Figure 4 almost all dimensions have to demonstrate some strong points, that is sub-dimensions in the leverage opportunity quadrants, none can be considered as a strong point for the overall satisfaction as the leverage opportunity (top-right) quadrant of the corresponding relative action diagram in Figure 5 is empty. Moreover, the majority of the dimensions present not only low performance but also low importance. The only dimension that presents high importance is the 'work tasks and development', but even this has a low performance, thus falling in the action opportunity (top-right) quadrant calling for attention and improvement; this particular dimension should be the number one improvement priority. On the other hand, the dimensions 'working hours and leaves' and 'supervisors' present high performance, but, due to their low importance for employees, fall in the transfer opportunity (top-left) quadrant of the diagram, thus becoming insignificant and indifferent from an improvement action point of view. All other dimensions, by demonstrating both low importance and performance, fall in the status quo (bottom-left) quadrant of the action diagram, indicating that they do not currently require any intervention. Nevertheless, it should not be forgotten that they require attention, as due to their low performance, they may become critical, should their importance increase for the employees in the future. Thus, they should become the number two improvement priority; just after the dimension 'work tasks and development'. Overall, this particular relative action diagram demonstrates gaps among the performance and importance of the considered dimensions that require attention.

Although the low relative importance observed in all but the 'work tasks and development' dimension may look surprising from a first sight, it should not be forgotten 
that despite the merger and the resulting changes, EFKA remains a public organisation. This means that certain aspects of its operation (e.g., working hours, earnings, infrastructure, etc.) will practically run the same way as before and employees are well aware of this. What however could radically change is the assignment of work tasks and the resulting development potential. Work tasks are typically assigned following the organisation structure defined through an organisation chart. In the case of EFKA, as mentioned earlier in Section 2, current operation runs under a temporal organisation chart, while the final one is still pending. This naturally creates some uncertainty to employees, which may, at least partially, explain the low relative performance observed in the respective job satisfaction dimension (see Figure 5).

Figure 5 Overall job satisfaction relative action diagram (see online version for colours)

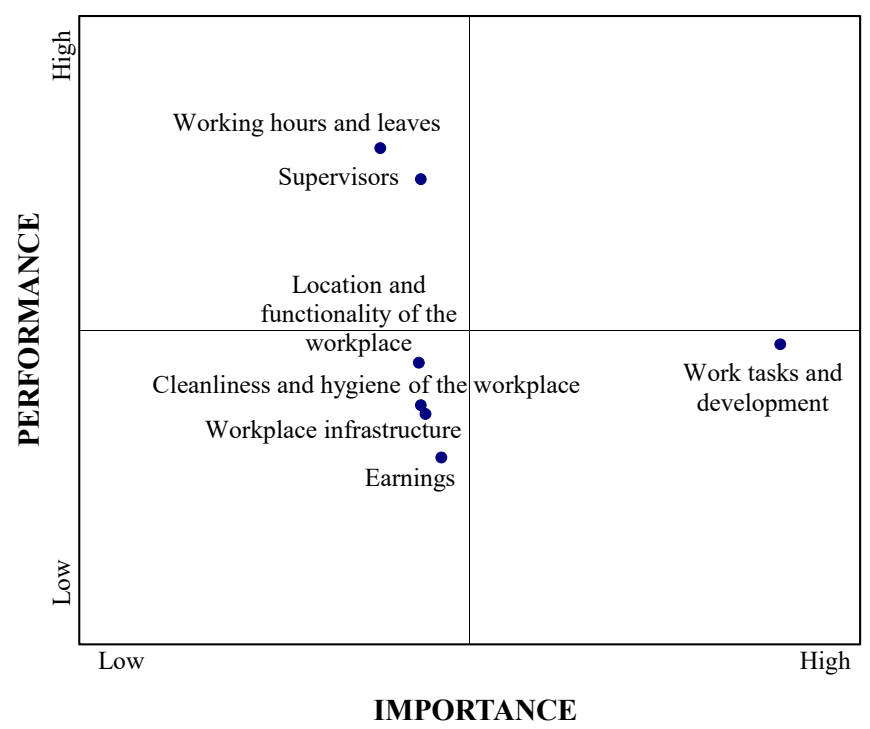

Looking globally the results of the performed analyses, it seems that the respondents to the survey expressed diverse views when focusing in the particularities of each considered job satisfaction dimension (see relative action diagrams of Figure 4). But when it came to the dimensions as a whole and to the overall job satisfaction dimension in particular, the expressed views became rather uniform and flat, highlighting not only low satisfaction levels but also low importance levels. Recall also that the majority of respondents reported that, overall, they are neither satisfied nor dissatisfied from their jobs (see Figure 3). This observed behaviour may be explained by the fact that EFKA employees keep a standby position, going through a period of adaptation to the new organisation scheme, while expecting and looking forward to the maturation of the changes already imposed, and those that are still to come, such as the final organisation chart, through the adopted top-down reorganisation approach. It may also be explained by the fact that in periods of generalised economic crises what really matters is the ability to have any employment that allows for decent living. However, as the survey results summarised in the relative action diagram of Figure 5 indicate, the current performance in a series of job satisfaction dimensions and overall is low, and may become critical for 
the organisational competence and performance, should the dimensions become more important for the employees in the future.

\section{Conclusions, limitations and future work}

The main aim of the study present herein was to explore and identify the job satisfaction determinants of EFKA employees, assess their current satisfaction levels and highlight job aspects, which are at critical state, thus require attention and/or improvement. To this end, a questionnaire survey was undertaken and the collected information was analysed with the use of statistical techniques, regression analysis in particular, and action diagrams.

The results of the analyses indicated that seven out of the ten initially considered dimensions have indeed a statistically significant contribution in explaining the overall satisfaction levels expressed by the respondents to the survey. These dimensions are in order of derived importance the 'work tasks and development', 'earnings', 'workplace infrastructure', 'cleanliness and hygiene of workplace', 'supervisors', 'location and functionality of workplace', and 'working hours and leaves'. From these dimensions, however only 'supervisors' and 'working hours and leaves' present high relative performance with respect to expressed satisfaction. All the other dimensions present low relative performance and call for attention, with the dimension 'work tasks and development' being the number one priority for improvement actions, as it has been found to be the most important job satisfaction dimension. Several other dimensionspecific aspects have been also found to call for attention and/or improvement.

The study has provided interesting and useful insights on the determinants of job satisfaction for the EFKA employees and the directions where the improvement efforts and actions of the newly shaped agency may focus in order to preserve and/or improve the employee satisfaction, thus preserving and/or improving its own competence and performance. Nevertheless, it presents some limitations that prevent generalisations, and give rise to several directions for future research and development.

To start with, the survey was limited to a specific geographical area and a subset of the total population of employees. As a consequence, despite the effort made, there are no guarantees that the collected sample is truly representative of the perceptions of the total population of EFKA employees. It is therefore recommended for the future, the extension of the survey at a national-wide level.

Another limitation of the study comes from the employed analysis techniques. For the derivation of the job satisfaction dimensions and sub-dimensions, which are important for that shape the overall job satisfaction employees, a series of regression models were developed at two independently considered levels. At the lower level, ten independent regression models were developed and used in order to derive the important subdimensions for each considered dimension, while at the upper level, one regression model was developed and used to reveal the dimensions that are most important for the overall job satisfaction without taking into account the performance at their respective subdimensions. This approach ignores any potential contributions of the sub-dimensions in determining the overall job satisfaction via their contributions in determining the satisfaction at their respective dimensions. This problem may be overcome by the adoption of a hierarchical linear modelling approach, whereby the contributions of the 
aforementioned two levels in determining overall job satisfaction could be simultaneously taken into account. The development and use of such a model would also be an interesting extension of the present study.

Last not least, an interesting future extension would be to study the considered problem via the employment of advanced techniques such as the multi-criteria satisfaction analysis (MUSA) method, which has been specifically developed to address the satisfaction measurement and assessment problem (Grigoroudis and Siskos, 2010).

\section{Acknowledgements}

The authors thank the Single Agency for Social Insurance of Greece for the permission granted to run the questionnaire survey reported herein. The contents of the paper reflect the views of the authors, who are responsible for the accuracy of the data presented herein.

\section{References}

Bakotić, D. (2016) 'Relationship between job satisfaction and organisational performance', Economic Research-Ekonomska Istraživanja, Vol. 29, No. 1, pp.118-130.

Bateh, J., Castaneda, M.E. and Farah, J.E. (2013) 'Employee resistance to organizational change', International Journal of Management and Information Systems, Vol. 17, No. 2, pp.113-116.

Chaudhary, N.S. and Bhaskar, P. (2016) 'Training and development and job satisfaction in education sector', International Journal of Business Quantitative Economics and Applied Management Research, Vol. 2, No. 8, pp.89-97.

Chaudhuri, K., Reilly, K.T. and Spencer, D.A. (2015) 'Job satisfaction, age and tenure: a generalized dynamic random effects model', Economics Letters, May, Vol. 130, pp.13-16.

Cranny, C.J., Smith, P.C. and Stone, E.F. (1992) Job Satisfaction: How People Feel about Their Jobs and How It Affects Their Performance, Lexington Books, New York.

Demoussis, M. and Giannakopoulos, N. (2007) 'Exploring job satisfaction in private and public employment: empirical evidence from Greece', Labor, Vol. 21, No. 2, pp.333-359.

Fassoulis, K. and Alexopoulos, N. (2015) 'The workplace as a factor of job satisfaction and productivity: a case study of administrative personnel at the University of Athens', Journal of Facilities Management, Vol. 13, No. 4, pp.332-349.

Field, A. (2009) Discovering Statistics using SPSS, Sage, London.

Frost, J. (2017) How to Interpret R-squared in Regression Analysis [online] http://statisticsbyjim.com/regression/interpret-r-squared-regression/ (accessed 19 July 2018).

Furst, S.A. and Cable, D.M. (2008) 'Employee resistance to organizational change: managerial influence tactics and leader-member exchange', Journal of Applied Psychology, Vol. 93, No. 2, pp.453-462.

González, F., Sánchez, S.M. and López-Guzmán, T. (2016) 'The effect of educational level on job satisfaction and organizational commitment: a case study in hospitality', International Journal of Hospitality and Tourism Administration, Vol. 17, No. 3, pp.243-259.

Grigoroudis, E. and Siskos, Y. (2010) Customer Satisfaction Evaluation: Methods for Measuring and Implementing Service Quality, Springer, New York.

Gustafsson, C.H. and Östberg, A-L. (2017) 'Experiences from the merger of clinics in the Swedish public dental service - the employee perspective', The Open Dentistry Journal, Vol. 11, pp.503-511. 
Harper, E., Castrucci, B.C., Bharthapudi, K. and Sellers, K. (2015) 'Job satisfaction: a critical, understudied facet of workforce development in public health', Journal of Public Health Management and Practice, Vol. 21, No. 6, pp.S46-S55.

Judge, T.A., Piccolo, R.F., Podsakoff, N.P., Shaw, J.C. and Rich, B.L. (2010) 'The relationship between pay and job satisfaction: a meta-analysis of the literature', Journal of Vocational Behavior, Vol. 77, No. 2, pp.157-167.

Locke, E.A. (1976) 'The nature and causes of job satisfaction', in Dunnette, M.D. (Ed.): Handbook of Industrial and Organizational Psychology, pp.1297-1349, Rand McNally, Chicago.

Lu, H., Barriball, K.L., Zhang, X. and While, A.E. (2012) 'Job satisfaction among hospital nurses revisited: a systematic review', International Journal of Nursing Studies, Vol. 49 No. 8, pp.10-17.

Mafini, C. and Pooe, D.R.I. (2013) 'The relationship between employee satisfaction and organisational performance: evidence from a South African government department', $S A$ Journal of Industrial Psychology/SA Tydskrif vir Bedryfsielkunde, Vol. 39, No. 1, Art. \#1090, 9pp [online] http://dx.doi.org/10.4102/sajip.v39i1.1090.

Markovits, Y., Boer, D. and van Dick, R. (2014) 'Economic crisis and the employee: the effects of economic crisis on employee job satisfaction, commitment, and self-regulation', European Management Journal, Vol. 32, No. 3, pp.413-422.

Meimaridis, E. (2018) Job Satisfaction Assessment of Employees in the Single Agency for Social Insurance in Greece (EFKA), MBA dissertation, Hellenic Open University, Patra, Greece.

Mottaz, C. (1984) 'Education and work satisfaction', Human Relations, Vol. 37, No. 11, pp.985-1004.

Neuman, K. (2003) 'The effect of organizational reengineering on job satisfaction for staff in hospital social work departments', Social Work in Health Care, Vol. 36, No. 4, pp.19-33.

OECD (2017) 'Women in public sector employment', in Government at a Glance 2017, OECD Publishing, Paris [online] https://doi.org/10.1787/gov_glance-2017-27-en (accessed 19 July 2018).

Ouedraogo, A. and Leclerc, A. (2013) 'Job satisfaction and organizational performance: evidence from Canadian Credit Union', Journal of Organizational Culture, Communications and Conflict, Vol. 17, No. 1, pp.35-50.

Pick, D. and Teo, S.T.T. (2017) 'Job satisfaction of public sector middle managers in the process of NPM change', Public Management Review, Vol. 19, No. 5, pp.705-724.

Raharjo, H., Mugion, R.G., Di Pietro, L. and Toni, M. (2016) 'Do satisfied employees lead to satisfied patients? An empirical study in an Italian hospital', Total Quality Management and Business Excellence, Vol. 27, Nos. 7-8, pp.853-874.

Schmidt, S.W. (2007) 'The relationship between satisfaction with workplace training and overall job satisfaction', Human Resource Development Quarterly, Vol. 18, No. 4, pp.481-498.

Spector, P.E. (1997) Job Satisfaction: Application, Assessment, Causes and Consequences, Sage, Thousand Oaks London New Delhi.

Zheng, X., Diaz, I., Tang, N. and Tang, K. (2014) 'Job insecurity and job satisfaction', Career Development International, Vol. 19, No. 4, pp.426-446. 